\title{
A AÇAO DO BAYGON (OMS-33) NO COMBATE AO PANSTRONGYLUS MEGISTUS
}

\author{
Italo A. Sherlock e Tácito M. Muniz
}

\begin{abstract}
Durante o ano de 1972 a 1975 o Baygon (OMS-33) 2 - isopropoxifenil - N - metil - carbamato foi utilizado no combate ao $P$. megistus numa pequena área de 200 casas no Estado da Bahia endémica para a doença de Chagas. Somente na dosagem de $1,6 \mathrm{mg} / \mathrm{m}^{2}$, em duas aplicaçóes anuais, os resultados foram considerados satisfató. rios. Devido ao elevado custo do produto, é considerado que ele não possa ser utilizado em campanhas profiláticas do governo, podendo entretanto ser utilizado por fazendeiros de recursos em suas próprias fazendas protegendo-se assim contra a proliferação dos vetores da Doença de Chagas.
\end{abstract}

Entre alguns inseticidas que têm sido usados para combater o Panstrongy/us megists, destacam-se o BHC e o Malathion 3.4.5. O Baygon (OMS-33), embora muito utilizado como inseticida doméstico contra vários tipos de insetos, somente tinha sido experimentado contra a $T$. infestans em outros paises sul-americanos. Desde que a Companhia Bayer do Brasil se dispôs a nos fornecer o inseticida necessário, realizamos testes para combater o $P$. megistus da doenca de Chagas em uma área endêmica do Estado da Bahia. Aqui apresentamos os resultados que obtivemos sobre a ação desse inseticida na luta contra aquele vetor.

\section{MATERIAL E METODOS}

O Baygon, nome comercial para produto Bayer 39007 ou OMS-33, é quimicamente o 2-isopropoxifenil - $\mathrm{N}$ - metilcarbamato, um pó cristalino branco, com um ligeiro odor do fenol, solúvel em águas e outros dissolventes : solares orgânicos, susceptível de hidrólise :m meio alcalino, sendo que em solução aquosa com $\mathrm{pH} 7$ se hidrolisa aproximadamente, $1,5 \%$ por dia.

Segundo os dados fornecidos pela Bayer, a sua toxidade é muito baixa, sendo a DL 50 oral para ratos aproximadamente de 100 $\mathrm{mg} / \mathrm{Kg}$, e para cobaia $40 \mathrm{mg} / \mathrm{Kg}$. A DL cutânea é praticamente nula; a DL 50 inalatoria para ratos gira em torno de $1000 \mathrm{mg} / \mathrm{m} 3$.

Não há praticamente toxidade crônica para ratos e cães, nem alterações hemáticas, nem das funções renal e hepática.

Para os insetos, já o Baygon é um tóxico gástico, tendo também uma forte acão pelo contacto, com notável rapidez letal. Muito importante também é seu efeito irritante e desalojante para os insétos em geral e aracnídeos.

O Baygon na apresentação comercial vem apenas com $50 \%$ do produto ativo puro.

As observações com o Baygon foram por nós realizadas numa pequena área do munjcípio de São Felipe, Estado da Bahia, infestada pelo $P$. megistus e hiperendẻmica para Doenca de Chagas. O programa inicial constava da borrifação de 78 casas uma vez por ano, com uma dose de $0,4 \mathrm{mg} / \mathrm{m}^{2}$ do produto ativo; mais 76 casas borrifadas duas vezes por ano com a dose de $0,4 \mathrm{mg} / \mathrm{m}^{2}$ e mais 57 casas borrifadas uma vez por ano com uma dose de $0,8 \mathrm{mg} / \mathrm{m}^{2}$ tendo ficado 77 casas sem borrifar para servir de controle (Tabela I). Tais concentraçōes embora muito mais bai$x$ as que as testadas por Schenone contra o $T$. infestans no Chile (2), foram-nos suger das pelo próprio Departamento Fitossanitário da Bayer.

Em janeiro de 1972 as áreas em observa. cões tinham sido previamente inspecionadas para triatomíneos, sem uso de desalojantes 
químicos, trabalhando-se 10 minutos em cada casa. Dessa forma, investigamos 246 domićlios dos 259 existentes, onde coletamos 167 triatomíneos. A media horária foi de 5,3 triatomíneos por hora. Todos os triatomfneos foram examinados para $T$. cruzi, obser. vando-se 0 indice de 13,3 de triatomíneos infectados.

Uma equipe composta por quatro auxiliares, sob a supervisão direta de um dos Auto. res, fez a primeira borrifação do total de 285 domićlios, usando-se a bomba Hudson $X$ Pert. Uma perte dos domicnios não foi borrifada, cuja intenção era de servir a mesma como controle, tendo essa sofrido apenas a inspecão para triatomídeos durante $10 \mathrm{mi}$ nutos após o uso de piriza.

Como o Baygon tinha potente ação desalojante para os insetos, após sua borrifação, esperava-se 10 minutos e fazia-se um levantamento da densidade dos triatomíneos, trabaThando-se aproximadamente 10 minutos em cada domicnio. Os resultados iniciais forneceram um índice global de 8,1 triatomíneos por hor , quando então foram coletados 463 exemplares de $P$. megistus, entre os quais 61 estavam infectados pelo $T$. cruzi (13,9\%) (Tabela III).

Em novembro de 1972 foi realizado o segundo ciclo de borrificação na área com pla. nejamento semestral. O método de trabalho foi o mesmo utilizado anteriormente. Foi então trabalhada a totalidade dos prédios existentes, tendo havido um crescimento vegetativo da ordem de $13 \%$ ou seja o número de prédios aumentou de 76 para 85 no período de seis meses (maio a novembro), nas duas localidades.

Em maio de 1973 foi realizado o $3{ }^{\circ}$ ciclo de borrificação nas áreas com programa semestral e 02 ? ciclo na área corn programa anual, seguindo-se a mesma orientação ante rior (Tabela IV).

Em vista de várias casas continuarem positivas para triatomineos $(16,6 \%)$, entre elas algumas infestadas desde 0 inicio das observações com esse inseticida, decidiu-se reformular a programação, aumentando-se as concentrações do inseticida, conforme a Ta. bela II.

Ficou planejado então o início das borrifaçōes com o novo esquema para agosto de 1973. Contudo, em vista da falta de verba para realizações dos trabalhos, assim como também da falta do recebimento de nova quantidade de inseticida, houve um intervalo de sete meses sem haver borrifações. Somente em novembro de 1973, iniciou-se o novo ciclo de aplicações semestrais e anuais com as concentrações mais elevadas, os quais perduraram por um ano, conforme a tabela II. Foram realizados mais trés círculos de borrifacóes ou seja em novembro de 1973, maio de 1974 e novembro de 1974. Em fevereiro de 1975, foi feita a última aplicação de Baygon com um levantamento glo. bal para a avaliação dos resultados.

\section{RESULTADOS}

Inicialmente, foram borrifadas 285 residências quando encontraram-se $22,8 \%$ de casas com $P$. megistus e entre elas $33,8 \%$ com o inseto infectado pelo $T$. cruzi. Foram coletados 463 exemplares, de $P$. megistus dando uma média horária de 8,4 triatomíneos por hora e $13,9 \%$ deles infectados pelo T.cruzi. (Tabela III).

$\mathrm{Na}$ área controle, onde simultaneamente só se usou piriza, a inspeção revelou $21,6 \%$ de casas com triatomíneos, $6.2 \%$ delas com triatomíneos infestados pelo $T$. cruzi. Foram coletados 102 exemplares de $P$. megistus dando uma média horária de 7,6 triatomfneos e entre eles $1,2 \%$ de positivos para $T$. cruzi.

$\mathrm{Na}$ realidade, com o primeiro esquema de trabalho, mesmo utilizando-se baixas concentraçōes de Baygon, houve inicialmen. te uma queda acentuada no índice de casas infestadas, conforme os dados abaixo e os das tabelas III e IV.

Entretanto, também na área controie, o índice de infestação caiu de $21,6 \%$ para $11,5 \%$. Como muitas das casas inicialmente infestadas permaneceram assim após as borrificaçōes, as concentrações do inseticida foram entâo aumentadas, conforme os dados da Tabela II iniciando-se o novo ciclo de observações. Resolyemos nessa mesma oportunidade investigar qual a causa de ter havido também uma queda na densidade de casas infestadas da área controle sem borrifaçāes, através da realizaçâo de questionários casa por casa. Verificamos então que nessa área, medidas de combate ao setor tinham sido feitas pela iniciativa privada dos próprios moradores que usaram meios diversos para combater os triatom íneos, inclusive inseticidas domésticos. Os resultados que obtivemos com o novo programa reformulado, são os apresentados nas Tabelas $V-V I$ - VII. 
Como se pode verificar na segunda parte das observações, apesar das concentraçōes de inseticidas terem sido mais elevadas, as quedas nos índices de casas infestadas não foram tăo acentuadas como as obtidas inicialmente.

Os percentuais de casas que permaneceram infestadas após as últimas aplicações do inseticida, foram bem elevados, demonstrando cerca de 0 a $20,5 \%$ delas infestadas e uma densidade de 0 a 8,2 triatomíneos por hora nesses áreas testadas. Portanto, no final das observaç̃es as diferenças dos resultados das áreas testes para aqueles obtidos nas áreas controles, não foram muito significantes, embora tenha havido uma queda nas taxas de infestação, conforme os dados abaixo resumidos e que săo vistos com detalhes nas tabelas $\mathrm{V}$ a VII. Foram entretanto mais acentuados os resultados da área onde foram realizadas 2 borrifações anuais com a concentração de $1,6 \mathrm{mg} / \mathrm{m}^{2}$ (Quadro )).

QUADRO I: AREAS TRABALHADAS E RESULTADOS GERAIS OBTIDOS

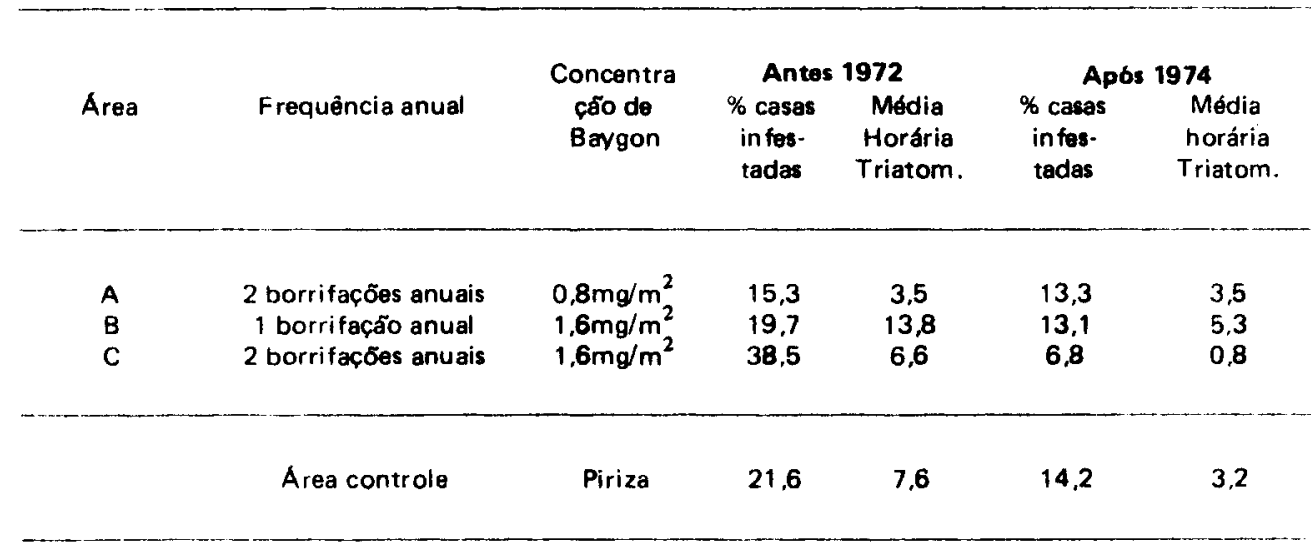

QUADRO II: GASTOS COM PESSOAL EMPREGADO NO EXPERIMENTO COM BAYGON

\begin{tabular}{|c|c|c|c|c|c|}
\hline PESSOAL & \multicolumn{2}{|c|}{$\begin{array}{l}\text { Salário } \\
\text { Dia Cr\$ }\end{array}$} & \multicolumn{2}{|c|}{$\begin{array}{l}\text { Alimentacão } \\
\text { e pousada Crs }\end{array}$} & $\begin{array}{l}\text { Total } \\
\text { Cr\$ }\end{array}$ \\
\hline $\begin{array}{l}1 \text { Supervisor } \\
2 \text { Guardas } \\
1 \text { Motorista }\end{array}$ & $\begin{array}{l}\mathrm{Cr} \$ \\
\mathrm{Cr} \$ \\
\mathrm{Cr} \$\end{array}$ & $\begin{array}{l}67,83 \\
17,70 \\
17,70\end{array}$ & $\begin{array}{l}\mathrm{Cr} \$ \\
\mathrm{Cr} \$ \\
\mathrm{Cr} \$\end{array}$ & $\begin{array}{l}84,65 \\
41,76 \\
45,60\end{array}$ & 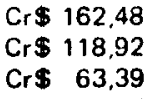 \\
\hline $\begin{array}{l}\text { TOTAL: } \\
\text { Combustivel } \\
4.692 \text { Gs. Baygon a } \mathrm{Cr} \$ 66,33\end{array}$ & \multicolumn{2}{|c|}{$\mathrm{Cr} \$ 103,23$} & \multicolumn{2}{|c|}{$\mathrm{Cr} \$ 182,10$. } & $\begin{array}{l}\operatorname{Cr} \$ 344,79 \\
\operatorname{Cr} \$ 49,16 \\
\operatorname{Cr} \$ 311,00\end{array}$ \\
\hline TOTAL GERAL: & & & & & $\mathrm{Cr} \$ 704,95$ \\
\hline
\end{tabular}


TABELA 1

PLANO INICIAL de APLICACÁO E CONCENTAACÁO DE BAYGON PARA COMBATE AO P. MEGISTUS NO PROJETO INICIADO EM JANEIRO DE 1972

\begin{tabular}{|c|c|c|c|c|c|}
\hline AREA & $\begin{array}{l}N^{0} \text { de } \\
\text { Cases * }\end{array}$ & $\begin{array}{l}\text { Indice de } \\
\text { Infostacto } \\
\text { domicllier }\end{array}$ & $\begin{array}{c}\text { Grames de } \\
\text { Bayoon por } \\
\text { case ** }\end{array}$ & Frnquincia & $\begin{array}{c}\text { Dates das Aplicacóos } \\
\text { Anual da } \\
\text { borrifeça }\end{array}$ \\
\hline A & 73 & $9.7 \%$ & $200 \times 0,4=80$ & 1 vez & Maio 1972 - Maio 1973 \\
\hline B & 68 & $12,3 \%$ & $200 \times 0,4=80$ & 2 veres & $\begin{array}{c}\text { Maio } 1972 \text { - Maio } 1973 \\
\text { Novembro } 1972\end{array}$ \\
\hline$c$ & 51 & $25 \%$ & $200 \times 0,8=160$ & 1 vez & Maio 1972 - Maio 1973 \\
\hline Controle & 67 & $15,3 \%$ & APLICACĀC & DE PIRIZA & Janeiro 1972 - Maio 1973 \\
\hline
\end{tabular}

"- Houve construçôes e demoliçóes de casas durante as observaçóes.

* - Cálculo aproximado de uma casa $=200 \mathrm{~m}^{2}$; como o produ to comerciel É em mistura de $50 \%$, duplicou

\section{T A B ELAII}

PLANO INICIAL DE APLICACÁO E CONCENTRACÃ̃o DE BAYGON PARA COMBATE AOP. MEGISTUS NO PROJETO INICIADO EM NOVEMBRO DE 1973

\begin{tabular}{|c|c|c|c|c|c|}
\hline Area & $\begin{array}{l}N^{\circ} \text { de } \\
\text { Casas. }\end{array}$ & $\begin{array}{l}\text { Indice de } \\
\text { Infesteçöo } \\
\text { domicitiar }\end{array}$ & $\begin{array}{c}\text { Gramas de } \\
\text { Baygon por } \\
\text { case }\end{array}$ & $\begin{array}{l}\text { Frequincia } \\
\text { Anual ** }\end{array}$ & Datas das Aplicaçõas \\
\hline A & 81 & $19.7 \%$ & $200 \times 1,6=320$ & 2 vezes & $\begin{array}{c}\text { Novembro } 1973 \text { - Maio } 1974 \\
\text { Novembro } 1974\end{array}$ \\
\hline B & 84 & $9,8 \%$ & $200 \times 3.2=640$ & 1 ver & $\begin{array}{l}\text { Novembro } 1973 \text { - } \\
\text { Novembro } 1974\end{array}$ \\
\hline$C$ & 58 & $23 \%$ & $200 \times 3.2=640$ & 2 vezes & $\begin{array}{c}\text { Novembro } 1973 \\
\text { Maio } 1974 \text {-Novembro } 1974\end{array}$ \\
\hline Controle & 82 & $11,5 \%$ & APLICACÃ & DE PIRIZA & $\begin{array}{l}\text { Novembro } 1973 \\
\text { Novembro } 1974\end{array}$ \\
\hline
\end{tabular}

* Alguma casas foram demolidas e outras construidas durante o perf́odo de obsevaçóes.

* - Cálculo aproximado de uma casa $=200 \mathrm{~m}^{2}$; como o produ to comercial 6 em mistura de $50 \%$, duplicouse a dosagem. 
TABELA III

PESOUUEA PARA TRIATOMINEOS IMEDIATA A BORRIFACÃO COM O BAYGON (O.M.8. 33) EM MAIO DE 1972. NA AREA DE SAO FELIPE - BAHIA ENDÉMICA PARA DOENCA DE CHAGAS

\begin{tabular}{|c|c|c|c|c|c|c|c|c|c|c|c|c|c|}
\hline \multirow{2}{*}{ Areass } & \multirow{2}{*}{ Localidades } & \multicolumn{6}{|c|}{ CASAS } & \multicolumn{6}{|c|}{ TRIATOMINNEOS } \\
\hline & & $\begin{array}{l}\text { Exis- } \\
\text { tentes }\end{array}$ & $\begin{array}{l}\text { Borri- } \\
\text { fadas }\end{array}$ & $\begin{array}{l}\text { Com } \\
\text { Triato- } \\
\text { mineos }\end{array}$ & $\%$ & $\begin{array}{l}\text { Com } \\
\text { Triat. } \\
\text { Infec. }\end{array}$ & $\%$ & $\begin{array}{l}\text { Cole- } \\
\text { tados }\end{array}$ & $\begin{array}{l}\text { Horas } \\
\text { Gastas }\end{array}$ & $\begin{array}{l}\text { Modia } \\
\text { Horária }\end{array}$ & $\begin{array}{l}\text { Exami- } \\
\text { nados }\end{array}$ & $\begin{array}{l}\text { Po } \\
\text { tivo }\end{array}$ & $\%$ \\
\hline A & $\begin{array}{l}\text { Petiro } \\
\text { Panut } \\
\text { Timbo }\end{array}$ & $\begin{array}{r}41 \\
30 \\
7\end{array}$ & $\begin{array}{r}41 \\
30 \\
7\end{array}$ & $\begin{array}{l}4 \\
7 \\
1\end{array}$ & $\begin{array}{r}9,7 \\
23,3 \\
14,2\end{array}$ & $\begin{array}{l}1 \\
6 \\
i\end{array}$ & $\begin{array}{r}25,0 \\
35,7 \\
100,0\end{array}$ & $\begin{array}{r}21 \\
32 \\
4\end{array}$ & $\begin{array}{l}7,30 \\
7,00 \\
1,30\end{array}$ & $\begin{array}{l}2,8 \\
4,5 \\
2,6\end{array}$ & $\begin{array}{r}21 \\
32 \\
4\end{array}$ & $\begin{array}{r}1 \\
25 \\
3\end{array}$ & $\begin{array}{r}4,7 \\
78,1 \\
75,0\end{array}$ \\
\hline \multicolumn{2}{|c|}{ Sub - Total } & 78 & 78 & 12 & 15,3 & 8 & 66,6 & 57 & 16,00 & 3.5 & 57 & 29 & 50,8 \\
\hline $\mathbf{B}$ & $\begin{array}{l}\text { Ferreira } \\
\text { Cangatheiros }\end{array}$ & $\begin{array}{l}49 \\
27\end{array}$ & $\begin{array}{l}49 \\
27\end{array}$ & $\begin{array}{r}11 \\
4\end{array}$ & $\begin{array}{l}22,4 \\
14,8\end{array}$ & $\begin{array}{l}5 \\
1\end{array}$ & $\begin{array}{l}45,4 \\
25,0\end{array}$ & $\begin{array}{r}190 \\
37\end{array}$ & $\begin{array}{r}11.00 \\
5,20\end{array}$ & $\begin{array}{r}17,2 \\
7,1\end{array}$ & $\begin{array}{r}190 \\
37\end{array}$ & $\begin{array}{r}10 \\
1\end{array}$ & $\begin{array}{l}5,2 \\
2,7\end{array}$ \\
\hline \multicolumn{2}{|c|}{ Sub - Total } & 76 & 76 & 15 & 19,7 & 6 & 40,0 & 227 & 16,20 & 13,8 & 227 & 11 & 4,8 \\
\hline c & Sapezinho & 57 & 57 & 22 & 38,5 & 7 & 31,8 & 77 & 11,30 & 6,6 & 76 & 20 & 26,3 \\
\hline & - Total & 211 & 211 & 49 & 23,2 & 21 & 42,8 & 361 & 43,20 & 8,2 & 360 & 60 & 16,6 \\
\hline $\begin{array}{l}\text { Con- } \\
\text { trole }\end{array}$ & Genipapo & 77 & 74 & 16 & 21,6 & 1 & 6,2 & 102 & 13,20 & 7,6 & 77 & 1 & 1,2 \\
\hline & otal Geral & 288 & 285 & 65 & 22,8 & 22 & 33,8 & 463 & 56,40 & 8,1 & 437 & 61 & 13,9 \\
\hline
\end{tabular}

TABELA IV

PESQUUSA PARA TRIATOMINEOS IMEDIATA A BORRIFAÇÃO COM O BAYGON (O.M.8. 33) EM MAIO DE 1973, NA AREA DE SAO FELIPE - BAHIA ENDÉMICA PARA DOENCA DE CHAGAS

\begin{tabular}{|c|c|c|c|c|c|c|c|c|c|c|c|c|c|}
\hline \multirow{2}{*}{ Áreas } & \multirow{2}{*}{ Locatidedes } & \multicolumn{6}{|c|}{ CASAS } & \multicolumn{6}{|c|}{ TRIATOMINEOS } \\
\hline & & $\begin{array}{l}\text { Exis- } \\
\text { tentes }\end{array}$ & $\begin{array}{l}\text { Barri- } \\
\text { fadas }\end{array}$ & $\begin{array}{l}\text { Com } \\
\text { Triato- } \\
\text { mineos }\end{array}$ & $\%$ & $\begin{array}{l}\text { Com } \\
\text { Triat. } \\
\text { Infec. }\end{array}$ & $\%$ & $\begin{array}{l}\text { Cole- } \\
\text { tados }\end{array}$ & $\begin{array}{l}\text { Horas } \\
\text { Gastas }\end{array}$ & $\begin{array}{l}\text { Módia } \\
\text { Horária }\end{array}$ & $\begin{array}{l}\text { Exami- } \\
\text { nados }\end{array}$ & $\begin{array}{l}\text { Posi- } \\
\text { tivo }\end{array}$ & $\%$ \\
\hline A & $\begin{array}{l}\text { Rexiro } \\
\text { Pequí } \\
\text { Timibé }\end{array}$ & $\begin{array}{r}38 \\
35 \\
8\end{array}$ & $\begin{array}{r}36 \\
32 \\
8\end{array}$ & $\begin{array}{l}7 \\
7 \\
1\end{array}$ & $\begin{array}{l}19,4 \\
21,8 \\
12,5\end{array}$ & $\begin{array}{l}2 \\
4 \\
0\end{array}$ & $\begin{array}{r}29,0 \\
57,1 \\
0,0\end{array}$ & $\begin{array}{l}14 \\
34 \\
15\end{array}$ & $\begin{array}{l}7,00 \\
8,00 \\
1,30\end{array}$ & $\begin{array}{r}2,0 \\
4,2 \\
11,5\end{array}$ & $\begin{array}{l}14 \\
34 \\
15\end{array}$ & $\begin{array}{r}2 \\
11 \\
0\end{array}$ & $\begin{array}{r}14,2 \\
32,3 \\
0,0\end{array}$ \\
\hline \multicolumn{2}{|c|}{ Sub - Total } & 81 & 76 & 15 & 19.7 & 6 & 40.0 & 63 & 16,30 & 3,8 & 63 & 13 & 20.6 \\
\hline B & $\begin{array}{l}\text { Forneira } \\
\text { Cangal heiros }\end{array}$ & $\begin{array}{l}54 \\
30\end{array}$ & $\begin{array}{l}51 \\
30\end{array}$ & $\begin{array}{l}3 \\
5\end{array}$ & $\begin{array}{r}5,8 \\
16,7\end{array}$ & $\begin{array}{l}1 \\
2\end{array}$ & $\begin{array}{l}33,3 \\
40,0\end{array}$ & $\begin{array}{r}36 \\
8\end{array}$ & $\begin{array}{r}11,00 \\
8,30\end{array}$ & $\begin{array}{l}3,2 \\
0,9\end{array}$ & $\begin{array}{r}36 \\
6\end{array}$ & $\begin{array}{l}5 \\
3\end{array}$ & $\begin{array}{l}13,8 \\
50,0\end{array}$ \\
\hline \multicolumn{2}{|c|}{ Sub - Total } & 84 & 81 & 8 & 9,8 & 3 & 3.7 & 44 & 19,30 & 2,2 & 42 & 8 & 19.0 \\
\hline C & Sapezinho & 58 & 53 & 12 & 23,0 & 7 & 58.3 & 31 & 11,00 & 2,9 & 32 & 16 & 50,0 \\
\hline Total & & 223 & 210 & 35 & 16,6 & 16 & 45.7 & 138 & 47,00 & 2,9 & 137 & 37 & 27.0 \\
\hline $\begin{array}{l}\text { Con- } \\
\text { Trole }\end{array}$ & Genipapo & 82 & 82 & 9 & 11,5 & 3 & 33,3 & 182 & 22,00 & 8.2 & 175 & 38 & 21,0 \\
\hline & otal Geral & 305 & 292 & 44 & 15,2 & 19 & 43.2 & 320 & 69.00 & 4.6 & 312 & 75 & 24.0 \\
\hline
\end{tabular}




\section{TABELA V}

PESQUISA PARA TRIATOMINEOS IMEDIATA A BORRIFACÁO COM O BAYGON (O.M.S. 33) EM MAIO DE 1973, NA AREA DE SAO FELIPE - BAHIA ENDËMICA PARA DOENCA DE CHAGAS

\begin{tabular}{|c|c|c|c|c|c|c|c|c|c|c|c|c|c|}
\hline \multirow{2}{*}{ Areas } & \multirow{2}{*}{ Localidades } & \multicolumn{6}{|c|}{ CASAS } & \multicolumn{6}{|c|}{ TAIATOMINEOS } \\
\hline & & $\begin{array}{l}\text { Exis- } \\
\text { tentes }\end{array}$ & $\begin{array}{l}\text { Borri- } \\
\text { fadas }\end{array}$ & $\begin{array}{l}\text { Com } \\
\text { Triato- } \\
\text { mineos }\end{array}$ & $\%$ & $\begin{array}{l}\text { Com } \\
\text { Triat. } \\
\text { Infec. }\end{array}$ & $\%$ & $\begin{array}{l}\text { Cole- } \\
\text { tados }\end{array}$ & $\begin{array}{l}\text { Horas } \\
\text { Gastas }\end{array}$ & $\begin{array}{l}\text { Média } \\
\text { Horária }\end{array}$ & $\begin{array}{l}\text { Exami- } \\
\text { nados }\end{array}$ & $\begin{array}{l}\text { Posi- } \\
\text { tivo }\end{array}$ & $\%$ \\
\hline A & $\begin{array}{l}\text { Retiro } \\
\text { Pequi } \\
\text { Timb. }\end{array}$ & $\begin{array}{r}36 \\
34 \\
6\end{array}$ & $\begin{array}{r}36 \\
32 \\
6\end{array}$ & $\begin{array}{l}3 \\
2 \\
0\end{array}$ & $\begin{array}{l}8,3 \\
6,2 \\
0,0\end{array}$ & $\begin{array}{l}2 \\
2 \\
0\end{array}$ & $\begin{array}{r}66,6 \\
100,0 \\
0,0\end{array}$ & $\begin{array}{r}6 \\
10 \\
0\end{array}$ & $\begin{array}{l}6,00 \\
5,20 \\
1,00\end{array}$ & $\begin{array}{l}1,0 \\
2,0 \\
0,0\end{array}$ & $\begin{array}{l}3 \\
9 \\
0\end{array}$ & $\begin{array}{l}2 \\
9 \\
0\end{array}$ & $\begin{array}{r}60,0 \\
100,0 \\
0,0\end{array}$ \\
\hline \multicolumn{2}{|c|}{ Sub - Total } & 76 & 74 & 5 & 6.7 & 4 & 80,0 & 16 & 12,00 & 1,2 & 12 & 11 & 91,6 \\
\hline \multirow[t]{2}{*}{$\mathbf{B}$} & $\begin{array}{l}\text { Ferreira } \\
\text { Cangalheiros }\end{array}$ & $\begin{array}{l}52 \\
24\end{array}$ & $\begin{array}{l}52 \\
24\end{array}$ & $\begin{array}{l}5 \\
2\end{array}$ & $\begin{array}{l}9,6 \\
8,3\end{array}$ & $\begin{array}{l}1 \\
1\end{array}$ & $\begin{array}{l}20,0 \\
50,0\end{array}$ & $\begin{array}{r}17 \\
8\end{array}$ & $\begin{array}{l}9,00 \\
5,00\end{array}$ & $\begin{array}{l}1,8 \\
1,6\end{array}$ & $\begin{array}{r}15 \\
7\end{array}$ & $\begin{array}{l}6 \\
4\end{array}$ & $\begin{array}{l}40,0 \\
57,0\end{array}$ \\
\hline & ub -- Total & 76 & 76 & 7 & 9,2 & 2 & 28,5 & 25 & 14,00 & 1.7 & 22 & 10 & 45,0 \\
\hline \multirow[t]{2}{*}{ C } & Sapezintio & 54 & 54. & 7 & 12,9 & 0 & 0.0 & 15 & 8.00 & 1.8 & 9 & 0 & 0,0 \\
\hline & ub - Total & 206 & 204 & 19 & 9,3 & 6 & 31,5 & 56 & 34,20 & 1.6 & 43 & 21 & 48,8 \\
\hline \multirow[t]{2}{*}{$\begin{array}{l}\text { Con- } \\
\text { trole }\end{array}$} & Genipapo & 75 & 73 & 9 & 12,3 & 1 & 11.0 & 42 & 15,00 & 2,8 & 9 & 1 & 11.1 \\
\hline & otal Geral & 281 & 277 & 28 & 10,0 & 7 & 25,0 & 98 & 49,20 & 1,9 & 52 & 22 & 42,3 \\
\hline
\end{tabular}


TARELA VI

PESQUISAS PAFA TRIATOMINEOS IMEDIATA A BORRIFICACAO COM O

(BAYGON O.M.S. - 33) EM ULHO DE 1974 NA AREA

DE SAO FELIPE - BAHIA

\begin{tabular}{|c|c|c|c|c|c|c|c|c|c|c|c|c|c|c|c|c|}
\hline \multirow{2}{*}{ Área } & \multirow{2}{*}{ Localidades } & \multicolumn{9}{|c|}{ CAsAs } & \multicolumn{6}{|c|}{ TRIATOMINEOS } \\
\hline & & Exist & Borrf & $\%$ & $\begin{array}{l}\text { Com } \\
\text { Triat }\end{array}$ & $\%$ & $\begin{array}{l}\text { C/Triat } \\
\text { Infecta } \\
\text { do }\end{array}$ & $\%$ & Vestg & $\%$ & Col. & $\begin{array}{l}\text { Hores } \\
\text { Gasta }\end{array}$ & $\begin{array}{l}\text { Modia } \\
\text { Horé } \\
\text { ria }\end{array}$ & Ex. & Pos & $\%$ \\
\hline A & $\begin{array}{l}\text { Retiro } \\
\text { Pequi } \\
\text { Timbó }\end{array}$ & $\begin{array}{r}34 \\
35 \\
6\end{array}$ & $\begin{array}{r}34 \\
35 \\
6\end{array}$ & $\begin{array}{l}100,0 \\
100,0 \\
100,0\end{array}$ & $\begin{array}{l}0 \\
1 \\
0\end{array}$ & $\begin{array}{l}0,0 \\
0,28 \\
0,0\end{array}$ & $\begin{array}{l}0 \\
1 \\
0\end{array}$ & $\begin{array}{r}0,0 \\
100,0 \\
0,0\end{array}$ & $\begin{array}{l}3 \\
0 \\
0\end{array}$ & $\begin{array}{l}0,88 \\
0,0 \\
0,0\end{array}$ & $\begin{array}{l}0 \\
3 \\
0\end{array}$ & $\begin{array}{l}900 \\
8.00 \\
1: 14\end{array}$ & $\begin{array}{l}0,0 \\
0,37 \\
0,0\end{array}$ & $\begin{array}{l}0 \\
3 \\
0\end{array}$ & $\begin{array}{l}0 \\
3 \\
0\end{array}$ & $\begin{array}{r}0,0 \\
100,0 \\
0,0\end{array}$ \\
\hline Sub-Total & & 75 & 75 & 100,0 & 1 & 1,3 & 1 & 1,3 & 3 & 4,0 & 3 & $18: 14$ & 0,01 & 3 & 3 & 100,0 \\
\hline C & Sapezinho & 59 & 59 & $100, a$ & 2 & 0,33 & 1 & 50,0 & 2 & 0,33 & 7 & 15.22 & 0,04 & 7 & 6 & 85,0 \\
\hline Total Gera & & 134 & 134 & 100,0 & 3 & 0,22 & 2 & 66,6 & 5 & 0,37 & 10 & $33: 16$ & 0,30 & 10 & 9 & 90 \\
\hline
\end{tabular}


TABELA VII

PESQUISA PARA TRIATOMINEOS IMEDIATA A BORRIFICACÃO COM O BAYGON (O.M.S. 33) EM FEVEREIRO DE 1975 NA AREA DE SAOO FELIPE - BAHIA ENDÊMICA PARA DOENCA DE CHAGAS

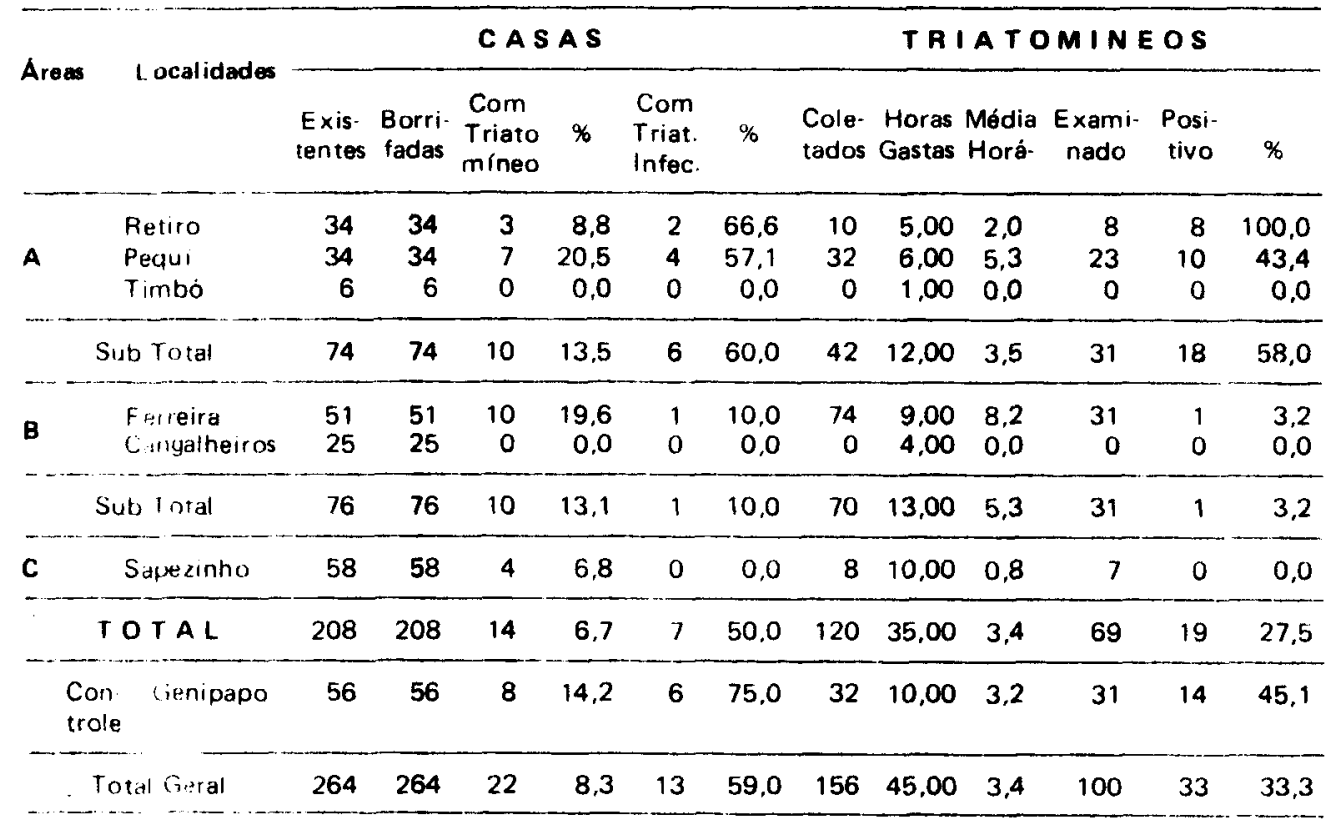

\section{CUSTO OPERACIONAL}

Quanto au custo operacional do Baygon, utilizando os dados gerais obtidos das borrifações em 1973, pudemos encontrar o que segue acrescido dos dados do Quadro 11.

Preço do Kilugrama de Baygon $\mathrm{Cr} \$ 66,33$ Baygon gasto por casa .....276 gramas Pessoal utilizado ........ 1 supervisor

\section{2 guardas} borrifadores

1 motorista

Nümero de casas borrifadas por

turma dia. . . . . . . 17.

Numero de casas borritadas por

homern dia $\ldots .8,5$ casas

Custo $p /$ casas trabalhada em $1973 \cdot \operatorname{Cr} \$$ 41,46 .

Foi possivel, com o Baygon observar-se o desejo e a aceitação da população com referência a aplicação do inseticida, não havendo recusas para impedir a sua borrifação. como é frequentemente observado com outros inseticidas. Não houve também quei$x$ as ou informações de reações colaterais e o povo gostava do odor do Bayyon. Entrentanto salientamos que em uma das aplicações do produto, foi necessária a utilização de antidotos para o tratamento de intoxicação aguda em duas pessoas, as quais contudo. apesar de alertadas, expuseram-se a forte doses do inseticida durante a sua aplicação. A quantidade de insetos $e$ aracnídeos que eram forcados a retirarem-se dos esconderi. jos devido a ação desalojante do Baygon dava a impressão de que sua eficácia era muito maior do que a real e isto muito contribui para que a população facilitasse a sua aplica. ção.

\section{COMENTÁRIOS E CONCLUSÕES}

Não existem na literatura referências sobre a experimentação do Baygon para combater triatomíneos no Brasil. Entretanto, esse inseticida foi experimentado noutros paises sul-americanos para combater o Triatoma infestans. Os resultados obtidos pelos Autores que o experimentaram nos países nossos vizinhos, foram por eles considerados bons. Isso possivelmente foi devido as dosagens elevadas e aos esquemas de aplicações freqüentes que empregaram. Entre- 
tanto, o cronograma de aplicações do Baygon com que Schenone e Cols ${ }^{2}$ obtiveram bons resultados no controle de $T$. infestans, não pôde ser adotado nas nossas experimentações. Tal esquema era impraticável de ser posteriormente aplicado nas áreas infestadas por triatomíneos do Brasil. Como sabemos, dentro da nossa estrutura burocrática funcional, só é possível de ser realizado um programa profilático com inseticidas, se o cronograma de aplicaçōes da substáncia exigir, no máximo intervalos semestrais. Já estávamos cientes de que, até mesmo em trabalhos experimentais em pequenas áreas, onde foi concentrado o máximo in. teresse do pessoal executante, algumas vezes não foi possivel obedecer o cronograma operacional planejado das aplicacões que tinham intervalos trimestrais. Portanto, para nós, apenas teórico o fato de que 0 inseticida quando reaplicado com intervalos de tempo mais curto seja muito mais eficaz, pois como salientamos, não poderá funcionar na prática.

O custo operacional do Baygon foi relativa. mente elevado. Enquanto que o BHC teve um custo operacional de cerca de $\mathrm{Cr} \$ 25,00$ e o do malathion de $\mathrm{Cr} \$ 26,50$, o do Baygon foi orcado em $\mathrm{Cr} \$ 41,46$ portanto bastante mais elevado, e isso devido quase que exclusivamente ao alto preço do produto.

Por um lado, o Baygon possue algumas condições mais vantajosas que os outros inse. ticidas que testamos, no que se refere a ser usado em campanhas de largo ámbito, a começar pela sua desalojante, a qual pode ser utilizado para os levantamentos de avaliação, economizando-se assim a utilização de piriza. Um outro fato também muito importante é o de ter o Baygon uma toxidade relativa. mente baixa. Durante os três anos de tra balhos com o mesmo, raros foram os fenô. menos de intoxicaçōes que observamos na nossa área de experimento. Se existe ação teratogenica, por efeito acumulativo ou tardio, ou de desenvolvimento lento, até agora não foi observado entre nós.

Um outro fator interessante è de que o Baygon tem um odor agradável e a sua ação desalojante para o inseto, que é imediata, impressiona muito bem aos moradores das residências onde está sendo aplicado. Isto significa facilita muito o prosseguimento da campanha com esse tipo de inseticida. Já observamos com outros inseticidas a ucorrência do inverso, quando alguns moradores, apesar de esclarecidos sobre os danos que os triatomíneos poderiam trazer, não permitiram a aplicação daquele inseticida que consideravam mais prejudiciais que os insetos vetores de doencas.

Em conclusão podemos dizer que, o Bay. gon, embora nas baixas concentrações e dilatados perfodos de aplicações que o utilizamos, não tenha móstrado grande eficácia contra o P. megistus, de certo modo poude controlar esse triatomíneo. Portanto, poderá ser considerado uma arma a mais para o combate aos vetores de Doenca de Chagas em determinadas circunstâncias. Evidente mente que, devido ao elevado custo, é pro. vável que não ofereça condições de ser utilizado em campanhas profilaticas de âmbito nacional. Entretanto, poderá muito bem ser utilizado pela iniciativa privada, particularmente por fazendeiros de recursos, que $o$ possam adquerir no comercio para uso em suas próprias fazendas, protegendo-se assim e aos seus moradores, contra a proliferação dos vetores da doença de Chagas.

From 1972 to 1975, 200 dwellings were spraved with Baygon (OMS-33) (2-isopropoxifenil-Nmetil-carbamate), to contro/ Panstrongylus megistus the vector of Trypanosoma cruzi in an endemic Chagas' disease area in the State of Bahia. Brazil. A dose of only $1.6 \mathrm{mg} / \mathrm{m}^{2}$ of Baygon spraved twice a year was considered satisfactory for controlling P. megistus. However, the high cost of Baygon prohibits its use on large scale control programs. Nevertheless, the Authors suggest that Baygon can be useful in eliminating vector bugs from individuals houses by those who can afford it. 


\section{REFERÊNCIAS BIBLIOGRAFICAS}

1) BAYER PELENZENSCHUTZ. LEVER. KUSEN - 1970 - BAYGON (Bayer 39.007, OMS-33) Informacion Tecnica. 10 p.o.

2) SCHENONE, H., VILLARROEL, F. \& KUNZ, E. - Ensayo de Control del Triatoma infestans en vivendas rurals mediante rociamientos com isopropoxifenil - $n$ metilcarbamato (OMS-33). Bol. Chile no Parasitol. 25 (3-4):143 - 146, 1970.

3) SHERLOCK, I. A., MUNIZ, T.M. \& GUITTON, M. - A açð̃o do Malathion sobre os ovos de Triatomíneos vetores de Doença de Chagas. Rev. Soc. Brasil. Med. Trop: $\times 177,1976$.

4) SHERLOCK, I. A., \& Muniz, T.M. Observaçס̃es sobre o combate ao $P$. megistus com BHC em área infestada do Estado da Bahia, Brasil. Rev. Brasil. Malar. D. Trop. 1974.

5) SHERLOCK, I. A. \& Muniz, T.M. - Combate ao Pentrongy/us megistus com o $\mathrm{Ma}$ lathion Concentrado. Rev. Soc. Brasil. Med. Trop.. IX 289, 1975. 